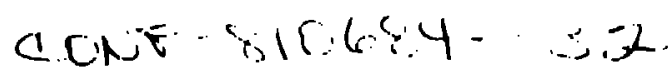

LA-UR -81-1659

TITLE: CALCULATIONS' OF CRATERING EXPERIMENTS WITH THE BEDDED CRACK MODEL

AUTHOR(S): LEONARD (i. MARGOLIN, (:-6

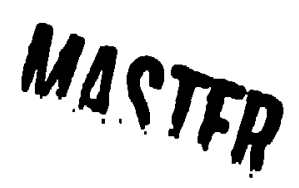

SUBMITTED TO: AMIRICAN PHYSICAI, SOC:LETY

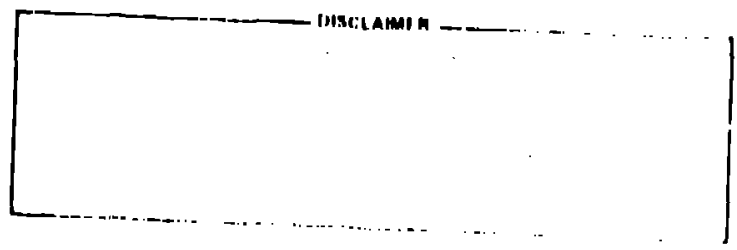

\begin{abstract}
By ecomence of this netecte, the publinher recogniens inat the US. Government restems o nonenclusive, roydiy lese lissense to sublish or renroduce the publishad form of inis conterthe non, or 10 dllow oiknn 10 to so, lor U.S Gomerment fiur nones:

The Los Alamos Scentific. Lebordory mejumis inat the puts,

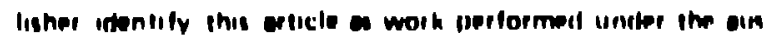

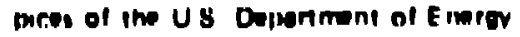




\section{CALCULATIONS OF CRATERING EXPERIMENTS WITH THE BEDDED CRACK MODEL}

\section{G. Margolin}

Los Alamos National Laboratory, Los Alamos, NM 87545

The YAQUI/BCM stress wave code is baing developed for the oll shale program. It purpose is to characterize explostve fracture In a brittle, or quasi-brittle, material. YAQUI is a finite difference hydrodvnamic code, based on the ALEl techntque, which we have converted to a solid mechantcs code. The BCM (bedded crack model) is the constitutive model. It is a statistical model that descrlbes frecture in terms of the growth of microcracks present in the competent material.

In addition to computer modeling, there !s an active program of large-scale field tests in oll shale. In this presentation, we wlll hegin hy describing the physlcal models upon which the BCM is basec. Then we will descrlbe calculations of a cratering event in the Coiny 0ll Shalo mine in Colorado. Based on the computer simulations, wh wlll outline the process of cratir formation.

Current technology for extricting ofl from the rock includes mining ihe rock, crushing: it, and processing the fragments in i surface retnrt. For envirnnmental as well as cconomli reasons, wo

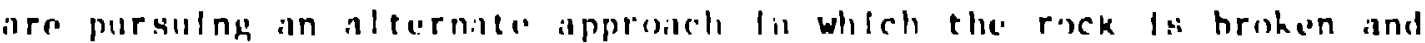
returtal in situ.

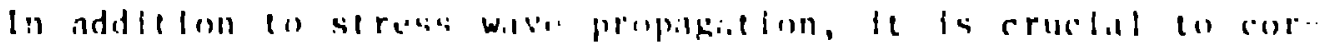
rectly descrlbe fragment sizo, porosles, and permeiabllity al the rraccired rock. Because of these requlrements, we have chosen en model the mleroscopla process of fracture in erems of crack growth

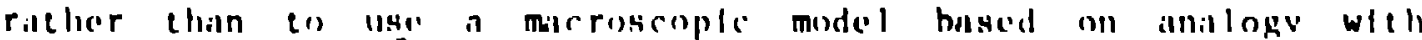

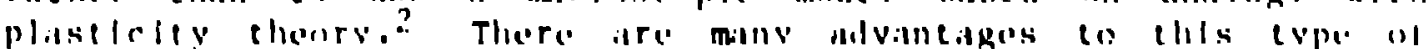

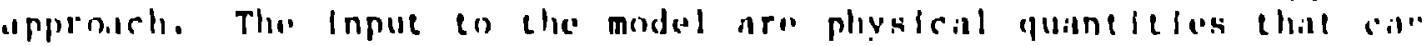

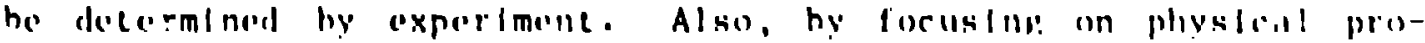

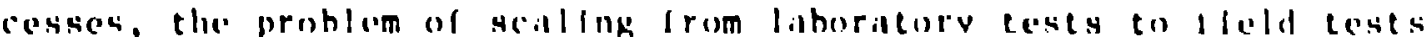

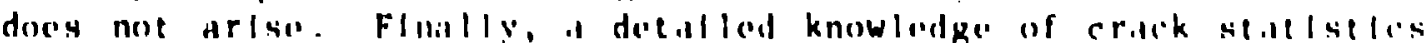

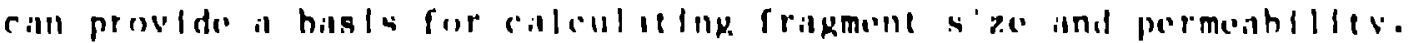

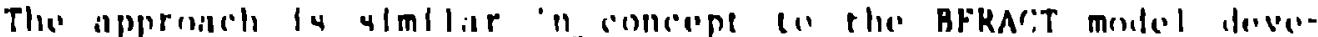

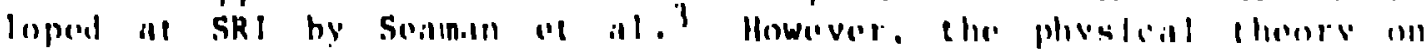

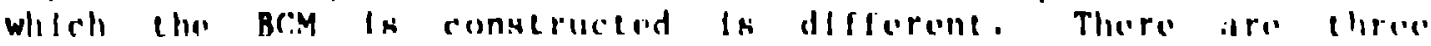

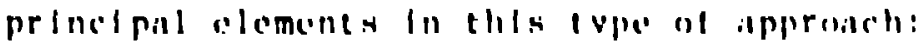

1) A cillorlon lor rerack krowth.

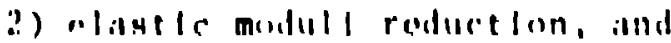

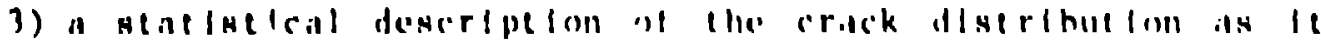
ovolivar lll $\mathrm{l} / \mathrm{mo}$.

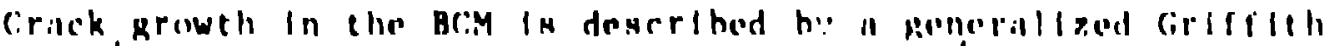

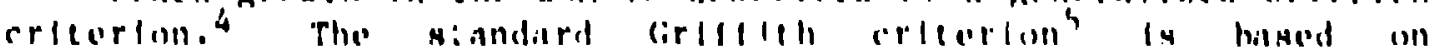

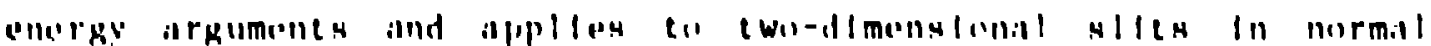

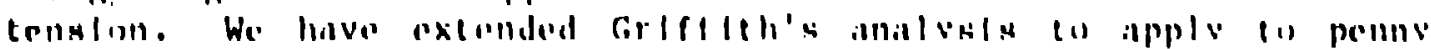

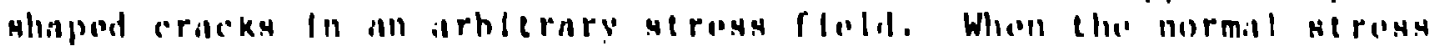

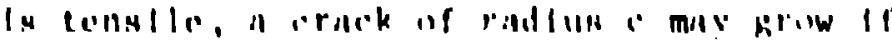




$$
\sigma_{\mathrm{zz}}^{2}+\left(\frac{2}{2-v}\right) \sigma_{\mathrm{rz}}^{2} \geqslant \frac{4 \pi \mathrm{TE}}{\mathrm{c}} \text {. }
$$

Here, $T$ is the surface energy of the materlal, $E$ is Young's modulus, and $\nu$ is Poisson's ratio.

What is new ard different about our generallzed criterion is that it predicts that a crack may grow in normal compression if the resolved shear is sufficlently large. In this case, the crack may grow if

$$
\left(\left|\sigma_{r z}\right|-\tau\right)\left(\ln _{r z} \mid-3 \tau\right) \geqslant\left(\frac{4 \pi T E}{c} \frac{2-v}{2}\right) .
$$

Here, $T$ is the frlctional stress between the crack faces, which we take as

$$
\tau=11 \mid z_{z 2} !,
$$

where is the coefflcient of triction.

The presence of cracks alters the elastic moduli of the material. The effective moduli ${ }^{4}$ are cound from static solutions for the displacement fleld for a body contalning a statistical distributior. of cricks, and subfected to a spitlally unlform, but otherwlse arbltrary stress ficld. The elastle modull are the elements of a fourth order tensor

$$
C_{1 j k i}=\frac{i r i j}{k l} \text {. }
$$

For cximplo, for a materlal contalning cracks bedied pilrillol to the $x-y$ plane, the effectlve component of compliance

$$
C_{z, 2 z 2}=\frac{C_{2 z z z}^{n}}{1+i r} .
$$

Here ryzz Is the modulus of the miterial matrlx and

$$
v 2 \frac{\mathrm{B}}{3}\left(1-\mathrm{V}^{2}\right) \overrightarrow{\mathrm{N}} \mathrm{C}^{3}
$$

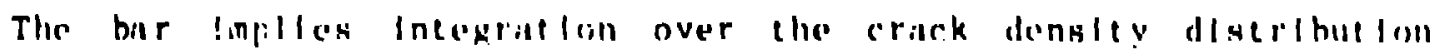
$N(c, 1)$.

As the cricks grnw, the dletrlbution evolves, ind Ho, and the effective modull vary in time. The conetleutlve relneion takes lhe form

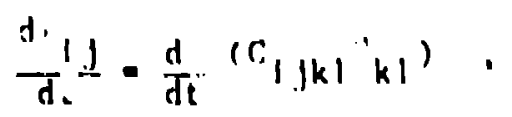

or 


$$
\frac{d \sigma_{k 1}}{d t}=\left(c^{-1}\right)_{k 11 j} \frac{d \varepsilon_{1 j}}{d t}-\left(C^{-1} j_{k 11 j} \dot{C}_{1 j m .1} \sigma_{m n}\right. \text {. }
$$

Thus, the constitutive relation has the form of a Maxwell solid with a variable relaxacion time.

The Inttial distribution of cracks is assumed to be exponential--the number of cracks with radius greater than $c$ is

$$
N_{u} \exp \left(-\frac{c}{i}\right)
$$

$N_{0}$ and $\bar{c}$ are materlal constants which are aetermined by measurement. This is the form assumed In BFRACT. However, the evolution of the distribution function in BCM differs in two essential features from BFRACT.

ritst, in BCM, only those cracks wilh radius greater than the critical radlus, as determined by the generalized criffith criterion, are allowed to grow. Thus, the distribution does not remaln exponential. This is in contrast to BFRACT in which all cracks grow when the stress exceeds a threshnld value.

Second, in the BCM, all cracks grow with the same specd, whlch is two-thlids of shear wave speed. Thls is an asymptotic approxlmation to Mote's result. ${ }^{h}$ The existence of a finlte velority fur crack propagation makes strain rate effects an intrinslc feature of the model.

The princlpal restriction of nur iudel lies in the assumptelon of hedded crictis. Oll shile is a hedded materlal, and we bollove that we aro modeling the wave propagatelon accuracely. However, to predlet frigment size and permeabllity, It wlll he necessiary to nllow for cricks of different orlentitlons. We are currently senerallzing the model in this regard.

Wr have slmulated minvactual craterlag events wlih YAQULI!BC.M. In a typlcil experiment, a $10 \mathrm{~cm}$ dlameter cullndrical horoliolo Is drllled vertically inte the mine finor. The linle is partlalls flllod with explosive, and the top of the hole is pirdiled. The axplosive is bottom dotonated, generating; shockwave that fractures the rock, and, dependlang on seiled depth of hurlal, llsuallv priduces il criter.

Figure I bhowe the Inlelal conilgurillon of a pitrelaulier experimelle, 7H-l. The doted line la the observed criter. The cruter is roughly a truncated cone wlet an npex hait-ingle of 145 ". In Plg. 2, the predicted reglon of frigmentilelon ls aliown with the observed irater superposed. One muse dletlnguish haeweren these proflles, for a frigment wlll he part of the reiter only if le hile sufflelone verelent velocity for ajectlon.

The computer almulation predicts the width and general mall:

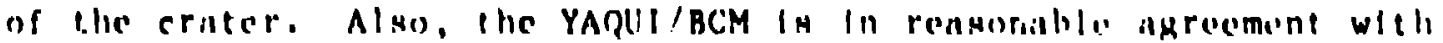

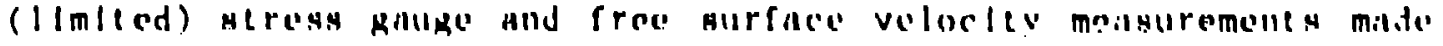

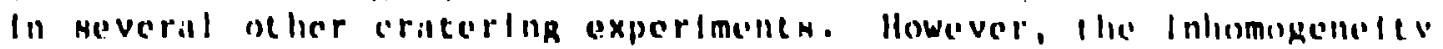
of the rock-thit is, olte mpectfle geology,--liads to a largo

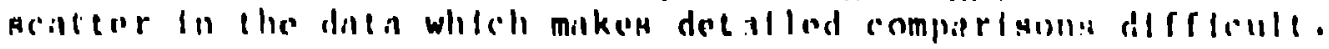


The cratering process can be understood in the following manner. The propagating burn in the explosive produces a confcal shnok rront in the rock. The angle of inclination to the horizonti ... the arc tangent of the ratio of detonation velocity co sound $s_{1}$ ied in the rock. The wave is compressive, and so the fracture is due to shear (Equation 2). In the cratering event 78-1, these speeds are about equal, and so this shock front inclination is about $45^{\circ}$. The maximum shear acting on horizontally bedded cracks is found on a conlcal surface, also with anex half angle of $45^{\circ}$.

The compressive wave produces a neart-shaped region of fracture around the charge (FIg. 3). The wave continues to the free surface where it reflects as a tensile rellef wave. The tension produces a spall region of additional fracture. Wher the two reglons overlap, a c:oter is produced.

In Fig. 4, we show a computer experiment in which the detonation velocity of the explosive is varied, keeping the total energy release flxed. The case with the larger detonation velocity is predicted to form a wider crater, with less damage above the borehole.

\section{REFERENCES}

I. C. W. HIrt, A. A. Amsden, and J.i. Cook, "An Arbltrary Lagringlan-Eulerinn Computing Muthod for All Flow Speeds," J. Comp. Phys. 14, ?27 (1974).

2. J. A. INlusion, "Cilleulation of Fxpluslve Rock Breakige: 011 Shale," Proc. 20th U.S. Symposium on Rock Mcchinles, Austin, Texas, June 4-6, 1979.

3. L. Stimiln, D. R. Curran, and D. A. Shockey, "Complitatlonil Methods for Ductllo and Brittle Frncture," I. Appl. Phys. 47, II (1976).

4. I. K. Dienes and I.. G. Margolln, "A Computational Approach to Rock Fragmentation," 2 lst U.S. Symposlum on Rock Mrchanles, Rolli1, Mlssouil, Mny 28-30, 1980.

5. J. F. Knote, Fundamentals of Fracture Mechanles (John WIley and Sons, Now York, 1973:.

h. F. N. Dunlianey and W. F. Brace, "Velnelty Gehilvlor of a Growlinb, Crack," J. Appl. Phys. 31, 2233 (196n). 


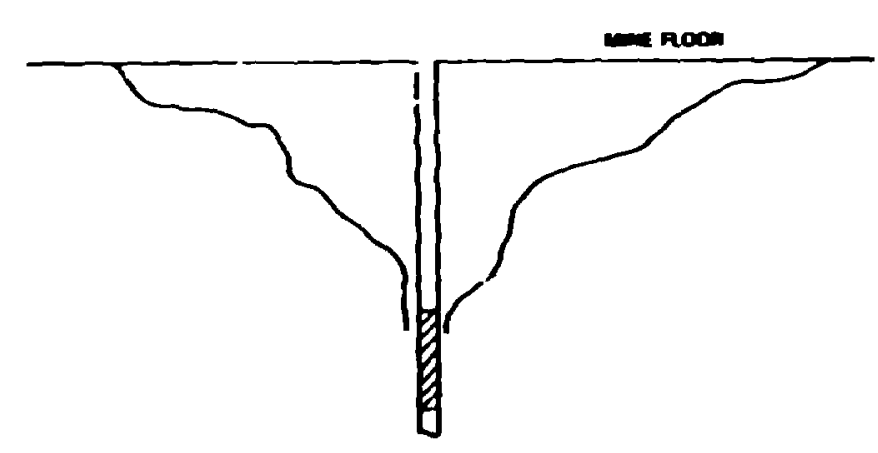

Fig. 1. Initial configuration of cratering experiment $78-1$ with final crater profile.

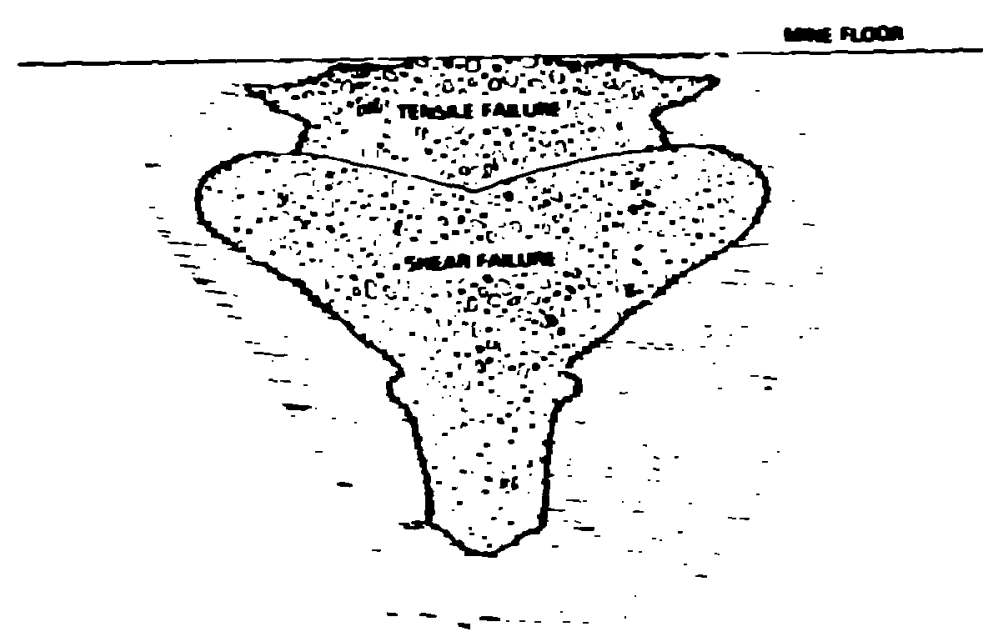

Fig. 3. Calculated fractured region of experiment 79-2. The water is formed from a shear failed region and a tensile failed region.

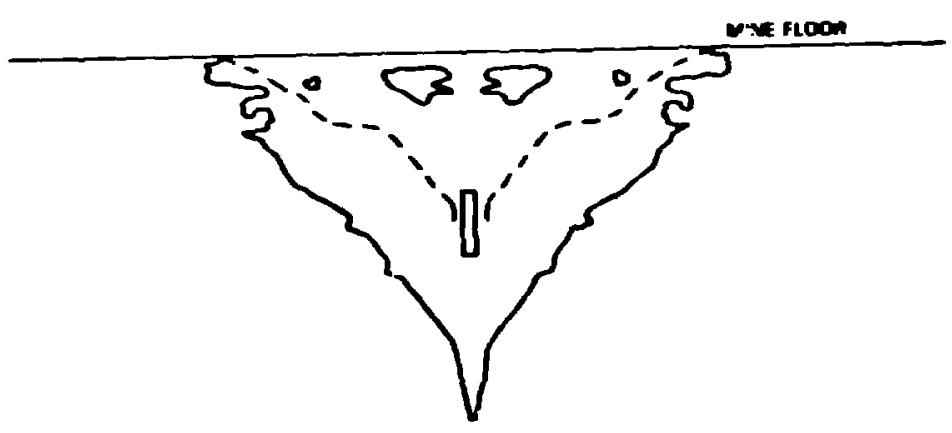

Fig. 2. Calculated fractured regior of experiment 78-1. Dotted line shows the ictual final crater profile.

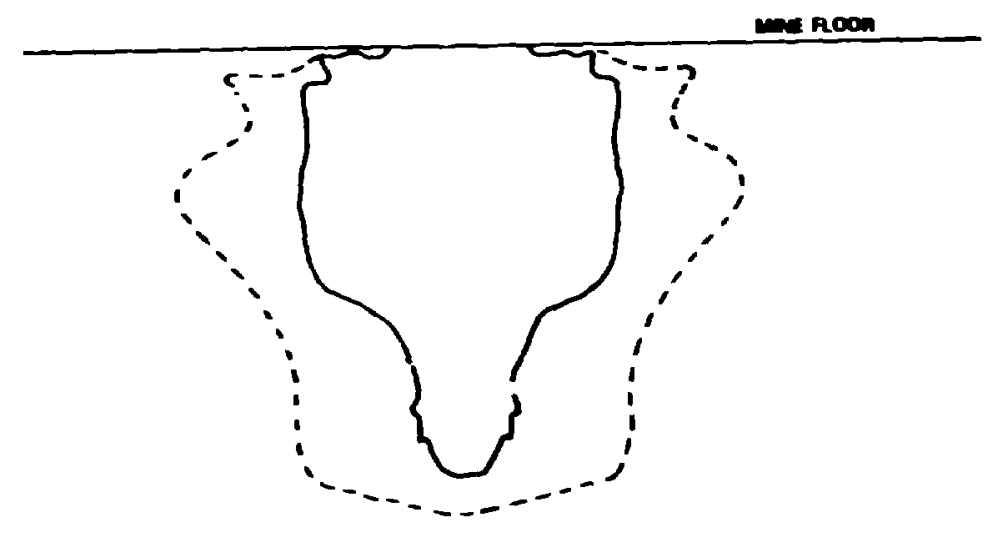

Fig. 4. Computer comparison of fractured regions for two experiments in which only the detonation speed of the explosive varied. The under region corresponds to a higher detonation speed. 